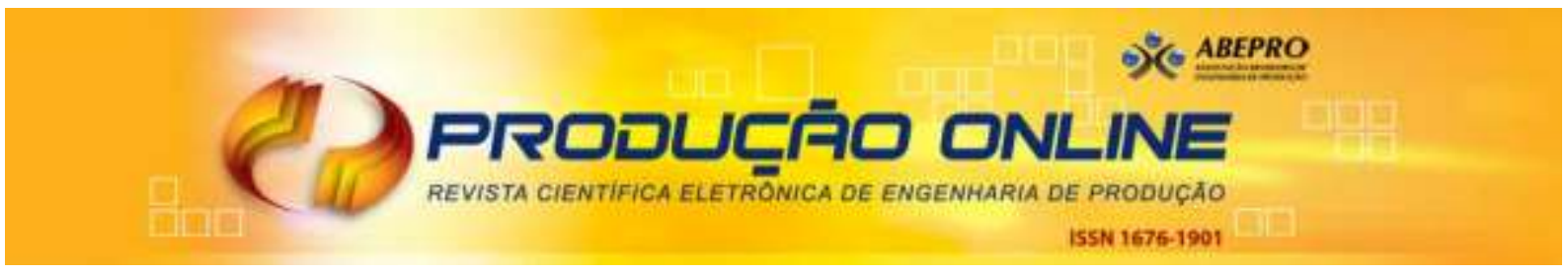

\title{
ANÁLISE DOS CUSTOS DA PRODUÇÃO POR MANUFATURA ADITIVA EM COMPARAÇÃO A MÉTODOS CONVENCIONAIS
}

\section{ADDITIVE MANUFACTURING COST ANALYSIS COMPARED TO CONVENTIONAL PRODUCTION METHODS}

\author{
Caio Mezzeti Giordano*Email: caio giordano@hotmail.com \\ Eduardo de Senzi Zancul* E-mail: ezancul@usp.br \\ Vinícius Picanço Rodrigues** E-mail: vipiro@dtu.dk \\ * Departamento de Engenharia de Produção, Escola Politécnica, Universidade de São Paulo (USP), \\ São Paulo, SP \\ ${ }^{* *}$ Departamento de Engenharia Mecânica, Technical University of Denmark (DTU), Dinamarca
}

\begin{abstract}
Resumo: A manufatura aditiva tem sido apontada como a tecnologia capaz de revolucionar os processos produtivos das empresas e de alterar as estratégias de produção atualmente empregadas. No entanto, hoje a manufatura aditiva ainda é essencialmente utilizada na produção de protótipos, em que se requer alta flexibilidade e baixos custos de ferramental específico. A tendência é que a manufatura aditiva passe a ser gradativamente utilizada como parte dos processos produtivos de produtos finais à medida que atinja maiores níveis de qualidade, tais como precisão dimensional, acabamento e tolerâncias, além de menores custos de produção, aproximando-se mais daqueles existentes na produção em larga escala. Neste cenário, este artigo visa analisar e comparar custos de produção para uma peça padrão produzida por meio de manufatura aditiva e por métodos convencionais de produção, analisando a viabilidade de implementação da tecnologia como parte essencial dos processos produtivos de empresas. A pesquisa proporciona também o estabelecimento de um padrão - peça padrão, suas características de projeto e volumes típicos de produção - a partir da qual análises periódicas possam ser realizadas ao longo dos próximos anos para avaliação de custos, com o aumento da escala e a consolidação da aprendizagem na produção dos equipamentos de manufatura aditiva.
\end{abstract}

Palavras-chave: Manufatura aditiva. Análise de Custos. Custos de Produção.

Abstract: Additive manufacturing has been identified as a technology that could revolutionize the production processes and change currently employed production strategies. However, additive manufacturing is still mainly used in the production of prototypes, in which high flexibility and low costs for specific tooling are required. The trend is that the additive manufacturing gradually becomes part of the production processes for final products as it reaches higher levels of quality, such as dimensional accuracy, finishing and tolerances, besides lower production costs, moving closer to those existing in the large-scale production. In this scenario, this paper aims to analyze and compare costs for a standard piece produced by additive manufacturing and conventional production methods, analyzing the feasibility of implementing the technology as an essential part of production processes. This research also provides the establishment of a standard piece, its design features and typical production volumes - from which periodic analysis should be conducted to evaluate costs, given the increasing scale and the learning curve consolidation in the production of additive manufacturing equipment.

Keywords: Additive manufacturing. Cost analysis. Production costs.

Revista Produção Online, Florianópolis, SC, v. 16, n. 2, p. 499-523, abr./jun. 2016. 


\section{INTRODUÇÃO}

A partir da década de 1980, começaram a surgir máquinas de prototipagem rápida (Rapid Prototyping - RP), conhecidas popularmente como impressoras 3D. Estes equipamentos são capazes de fabricar objetos por meio da adição de material, camada por camada, a partir de um modelo digital tridimensional (3D), usualmente realizado com o uso de um sistema CAD (Computer Aided Design). Assim, tem-se o conceito de produção por adição de material em contraste à produção por métodos convencionais, em que a peça é obtida pela retirada de material, em processos como a usinagem, por exemplo.

O termo prototipagem rápida provêm de uma das finalidades destas máquinas: produzir protótipos tridimensionais de produtos de uma maneira rápida e generalizada (CAMPBELL; BOURELL; GIBSON, 2012). Entretanto, hoje em dia, estes equipamentos não se limitam simplesmente à produção de protótipos, mas também à manufatura final de produtos. Portanto, a terminologia mais usual no âmbito técnico e adotada pela ASTM (American Society for Testing and Materials) é Manufatura Aditiva (Additive Manufacturing - AM) (GIBSON; ROSEN; STUCKER, 2009).

Algumas características fundamentais da manufatura aditiva são a redução do número de etapas e processos na fabricação de um objeto e a economia de material. Para a produção de uma única peça de geometria complexa por meios convencionais, pode ser necessário o emprego de diversas máquinas, ferramental específico e de diversos processos de usinagem e acabamento até obter o produto final. Por outro lado, utilizando a tecnologia de manufatura aditiva, é possível produzir a mesma peça em uma única etapa ou com a redução do número de etapas. Uma vez que a peça é produzida por deposição de material, há redução no descarte de materiais, como é o caso dos cavacos produzidos pelo processo de usinagem.

Assim, a manufatura aditiva serve como um meio para projetistas produzirem protótipos de seus projetos com objetivo de testá-los ou apresentá-los a colaboradores ou clientes de maneira rápida e eficiente. Além disso, este tipo de manufatura serve também para a produção de bens complexos, como próteses médicas personalizadas e, cada vez mais, mostra-se como um integrante da cadeia 
produtiva na indústria na produção de peças com geometria complexa (HOPKINSON, HAGUE e DICKENS, 2006).

As aplicações com sucesso da manufatura aditiva e consequente avanço na digitalização da produção na indústria levaram meios de comunicação como a revista britânica de abrangência internacional The Economist a ressaltarem a transformação dos meios de produção causadas por estas tecnologias. Para a The Economist (2012), avanços em manufatura aditiva poderão levar a uma nova revolução industrial, ressaltando o fato de que esta tecnologia não envolve economias de escala e, consequentemente, não pressupõe uma escala mínima de produção para que seja economicamente viável. Os custos seriam quase que totalmente variáveis (matéria-prima, energia etc.), o que significa que obter-se-ia praticamente o mesmo custo unitário de uma peça, seja ela sendo produzida em uma única unidade ou em milhares de unidades. Já a revista estadunidense de tecnologia e negócios Wired (2012) ressaltou a transformação no mercado de bens de consumo que a manufatura aditiva pode trazer, com produção de produtos tanto em âmbito local (local print), por meio de "impressoras" 3D instaladas nas casas de consumidores, quanto em âmbito global (global print), por meio de serviços de fabricação utilizando manufatura aditiva, como as empresas Shapeways e Ponoko.

Em um relatório sobre as principais tecnologias disruptivas, a McKinsey Global Institute (2013) coloca a manufatura aditiva como uma das 12 tecnologias que mais poderiam impactar a economia global até 2025. No relatório, reconhece-se o recente crescimento da tecnologia com uma redução de $90 \%$ do preço das máquinas de baixo custo e um aumento de $400 \%$ no faturamento da indústria nos últimos quatro anos. O relatório cita que o desempenho dos equipamentos de manufatura aditiva está melhorando rapidamente, com o desenvolvimento de novos materiais e redução do custo de fabricação.

Adicionalmente, Gartner et al. (2015) apresentam um estudo empírico baseado em avaliação de tecnologia para evidenciar as oportunidades que a manufatura aditiva pode trazer para políticas de inovação e de empreendedorismo tecnológico, oferecendo discussões sobre aspectos-chave de emprego, pesquisa e desenvolvimento em organizações e educação. Em um estudo mais especializado, Achillas et al. (2015) propõem um quadro referencial para a inclusão de tecnologias 
de manufatura para definição de estratégias de produção, levando em consideração uma série de critérios como custo de produção, lead time, qualidade etc.

Uma vez que o custo e viabilidade econômica são fatores decisivos na tomada de decisão de qualquer empresa, este artigo apresenta a definição de um padrão - peça padrão, suas características de projeto e volumes típicos de produção - a partir da qual possa-se realizar análises periódicas ao longo dos anos, com o objetivo de avaliar a redução de custos que devem ocorrer nos próximos anos com o aumento da escala e a consequente aprendizagem na produção dos equipamentos de manufatura aditiva.

O artigo apresenta uma revisão bibliográfica (Seção 2) sobre as principais tecnologias de produção por manufatura aditiva, seguido pela metodologia (Seção 3), resultados (Seção 4), conclusão e sugestão para trabalhos futuros (Seção 5).

\section{REVISÃO BIBLIOGRÁFICA}

Neste item são discutidas as principais características da manufatura aditiva (subseção 2.1) e apresentadas as principais tecnologias deste tipo de manufatura (subseção 2.2).

\subsection{Manufatura Aditiva}

Apesar de ainda existirem limitações quanto à qualidade das peças produzidas em comparação com os meios convencionais de produção, a manufatura aditiva já apresenta diversas características que têm tornado cada vez mais comum a sua aplicação. Para Sealy (2012), ainda há dúvidas quanto à integridade estrutural de produtos finais produzidos por manufatura aditiva. Entretanto, o autor ressalta que os benefícios desta tecnologia se sobrepõem às suas limitações. Segundo Berman (2012), a capacidade de produzir peças com design complexo, a facilidade de compartilhamento de projetos, a otimização da utilização de material, a produção automatizada e a capacidade de produzir peças funcionais são aspectos em que a manufatura aditiva se destaca. Holmström et al. (2010) acrescentam que a manufatura aditiva torna economicamente viável a personalização do design de 
cada produto fabricado, permite mudanças no design de um pequeno lote de peças com maior velocidade e proporciona uma cadeia logística simplificada.

Sealy (2012) ressalta ainda que é fundamental que o projetista tenha conhecimento das limitações dos processos produtivos empregados na fabricação do produto, bem como do maquinário empregado e as habilidades de fabricação dos funcionários para que possa ser mais eficiente em seu projeto. A manufatura aditiva, ao superar diversas das limitações dos processos produtivos convencionais, permitindo a produção de peças com geometria complexa, proporciona uma maior liberdade ao projetista que, desta forma, pode desenvolver sua criatividade com maior eficiência.

Apesar destas vantagens, Berman (2012) afirma que a manufatura aditiva possui como fatores limitantes: a menor precisão dimensional em relação aos métodos convencionais de produção; possuir ainda uma pequena variedade de materiais, disponibilidade limitada de cores e acabamentos superficiais; e resistência limitada à tensão, ao calor e à umidade elevada. Além disso, ressalta que para produção em massa de produtos, a manufatura aditiva ainda possui um custo elevado, o que pode colocar em risco os benefícios da ausência de economia de escala, se este custo não for devidamente equacionado. Se a máquina envolve investimento significativo, tal investimento precisa ser amortizado por uma produção relativamente alta, ainda que seja a partir de peças diversificadas.

De acordo com Hopkinson e Dickens (2003) os altos custos de equipamentos, manutenção e materiais constituem uma das principais barreiras à utilização da manufatura aditiva. Entretanto, os autores ressaltam que a crescente adoção da tecnologia pela indústria tem levado à redução de custos e ao surgimento de equipamentos menos caros no mercado, graças a economias de escala na produção destes equipamentos e a avanços tecnológicos, e que, com o crescimento do número de fornecedores e consequente intensificação da competição, deve haver redução do custo de materiais.

Adicionalmente, destaca-se que a produtividade dos equipamentos está aumentando de forma significativa. Por exemplo, empresas empregando a manufatura aditiva em peças finais buscam aumentos da velocidade de produção de vinte vezes nos próximos anos (CARTER ,2014). O aumento de produtividade levará à redução dos custos de produção. Kim et al. (2015) propõem um modelo para

Revista Produção Online, Florianópolis, SC, v. 16, n. 2, p. 499-523, abr./jun. 2016. 
definir e refinar parâmetros de processo em ambientes altamente dinâmicos ("manufatura inteligente"), oferecendo previsões sobre como a qualidade de uma determinada peça responderá às alterações deste tipo de ambiente. O modelo é acoplado com outros já consolidados em melhoria contínua, visando a uma utilização mais integrada pelas empresas.

Gibson et al. (2009) definiu oito etapas necessárias, em geral, para a produção utilizando manufatura aditiva, também representadas esquematicamente na figura 1:

1. Modelagem CAD (Computer-aided design): toda peça a ser produzida por manufatura aditiva deve ter sua a sua geometria externa definida por um modelo numérico (software). Para tanto, pode-se empregar praticamente qualquer software profissional de CAD ou sistemas e equipamentos de engenharia reversa (reverse engineering), como scanners a laser.

2. Conversão para STL (Surface Tessellation Language): o formato aceito em praticamente todos os equipamentos de manufatura aditiva é o STL, que é um padrão da indústria.

3. Transferência para a máquina de manufatura aditiva e manipulação do arquivo: o arquivo representando a peça deve ser transferido para 0 equipamento em que será produzida. Eventuais manipulações para corrigir o posicionamento, tamanho ou orientação da peça podem ser necessárias.

4. Configurar a máquina: pode ser necessário definir alguns parâmetros na máquina, como tempo de produção, a espessura das camadas, entre outros.

5. Produção: a produção por manufatura aditiva é automatizada e a supervisão por parte de um funcionário não é essencial, servindo apenas como garantia de que não haverá falta de material ou para atuar em eventuais problemas, como queda de energia ou outras oscilações.

6. Remoção: após o fim da produção, a peça deve ser retirada da máquina.

7. Pós-processamento: após a produção, podem ser requeridas atividades adicionais como a retirada de estruturas de suporte e limpeza. Tratamentos adicionais podem ser necessários para garantir qualidades estéticas à peça, como pintura e tratamentos de superfícies, ou as características físicas desejadas, como resistência e dureza.

8. Aplicação: a peça está pronta para ser usada.

Revista Produção Online, Florianópolis, SC, v. 16, n. 2, p. 499-523, abr./jun. 2016. 
Figura 1 - Etapas para produção de peça por manufatura aditiva

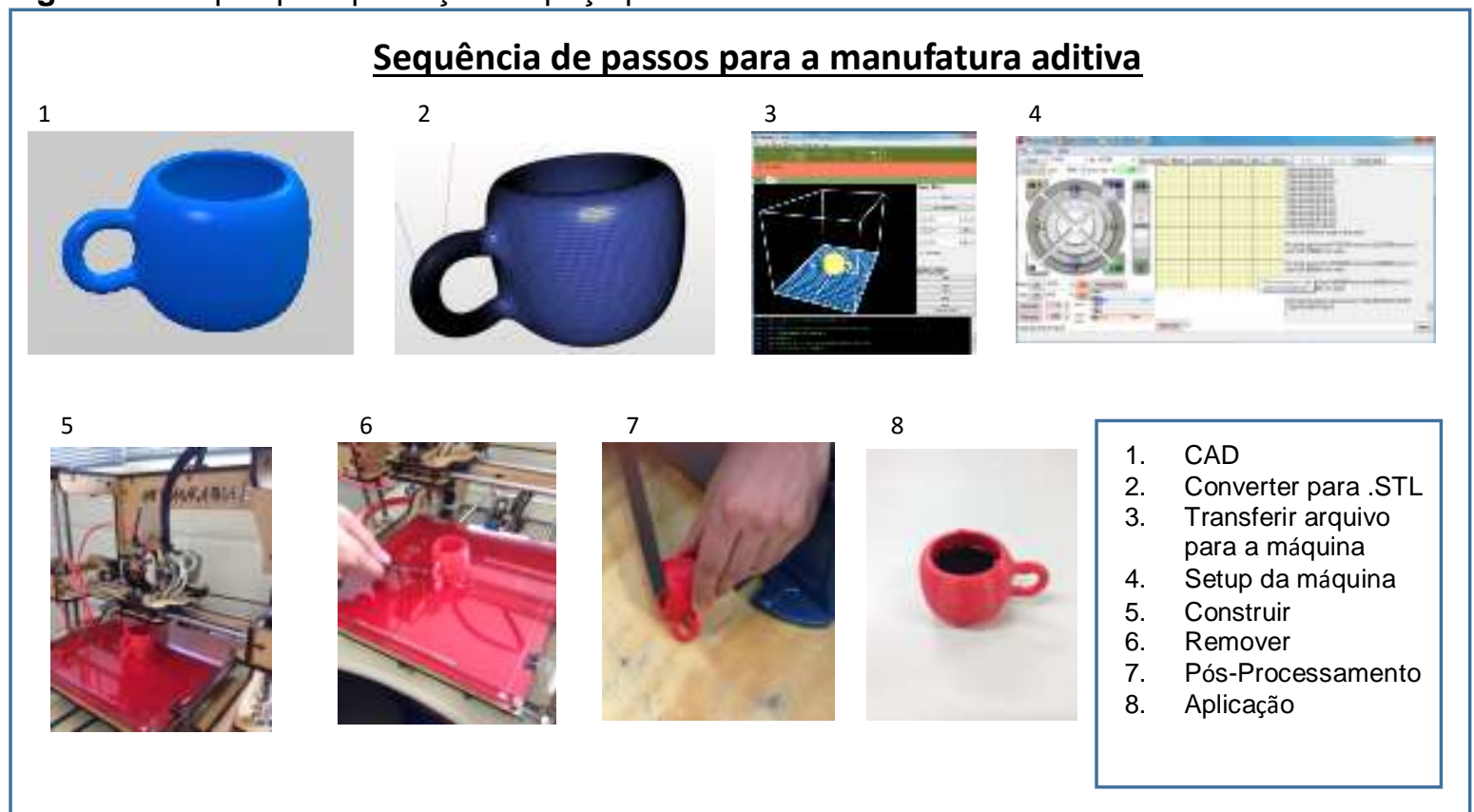

Fonte: Adaptado de Gibson et al. (2009)

Na próxima subseção são apresentadas as principais tecnologias e materiais para a manufatura aditiva.

\subsection{Principais Tecnologias e Materiais}

Desde a primeira máquina comercializada em 1988, mais de 30 diferentes técnicas e equipamentos de produção manufatura aditiva surgiram e foram comercializados, sendo aprimorados ao longo do tempo. Entretanto, nem todos são aplicáveis à manufatura aditiva de produtos finais devido à suas limitações materiais e mecânicas, sendo alguns voltados especificamente para a produção de protótipos com qualidades fundamentalmente estéticas.

As tecnologias de manufatura aditiva se subdividem em sistemas baseados em líquido, baseados em sólido e baseados em pó. Há, portanto, diferentes gamas de materiais com as quais estas tecnologias trabalham, além de produzirem produtos com características diferentes (CHUA; LEONG; LIM, 2010). As principais tecnologias de manufatura aditiva são estereolitografia (stereolithography - SLA), sinterização seletiva a laser (selective laser sintering - SLS), modelagem por deposição de material fundido (fused deposition modelling - FDM), modelagem por jato de tinta (inkjet printing - IJP) e impressão tridimensional (three-dimensional 
printing - TDP). Uma recente proposta de método para avaliação e seleção de tecnologias de manufatura aditiva, apoiada na técnica de Processo Analítico Hierárquico (Analytic Hierarchy Process - AHP) e baseada em especificações técnicas de peça pode ser encontrada no trabalho de Mançanares et al. (2015). A seguir, cada uma destas tecnologias é descrita.

\subsubsection{Estereolitografia (stereolithography - SLA)}

A estereolitografia é considerada a tecnologia que iniciou a revolução da prototipagem rápida, com a primeira patente emitida em 1986 para Charles W. Hull que, no mesmo ano, fundou a 3D Systems e lançou o primeiro equipamento no mercado em 1988 (CHUA; LEONG; LIM, 2010). Trata-se da produção de um objeto tridimensional por meio da foto-polimerização de uma resina líquida sobre uma plataforma pela incidência de um feixe de laser ultravioleta direcionado por um sistema de espelhos galvanométricos, causando, assim, o endurecimento da resina, formando a camada do produto final. Após a formação desta camada, a plataforma é abaixada em uma cuba preenchida com resina e uma nova camada de resina líquida surge sobre a anterior, reiniciando-se o processo até a formação final do objeto. Devido à alta viscosidade da resina, ativa-se um subsistema para nivelar a resina líquida sobre a plataforma, deixando-a plana. Após o processo de fabricação na máquina de SLA, o excesso de resina da peça é retirado com o emprego de um solvente, e inserido em fornos ultravioleta para aumentar o grau de cura da peça (LAN et al., 1997; MANÇANARES et al., 2015).

Ahrens et al. (2007) ressaltam que, dependendo da geometria do objeto a ser criado na SLA, suportes são criados automaticamente pela máquina para dar sustentação ao objeto que está sendo produzido, os quais devem ser retirados após a produção na máquina. Estes suportes são, geralmente, criados automaticamente pelo sistema computacional de planejamento de processo que acompanha o equipamento. Segundo os autores, existem diversos materiais fotocuráveis disponíveis atualmente, resinas a base de acrilatos (resina acrílica) e epóxi, sendo que as baseadas em epóxi são mais utilizadas por apresentarem menor contração de volume durante a produção e melhores propriedades mecânicas da peça. A figura 2 ilustra o processo da esterolitografia.

Revista Produção Online, Florianópolis, SC, v. 16, n. 2, p. 499-523, abr./jun. 2016. 
Figura 2 - Processo de estereolitografia

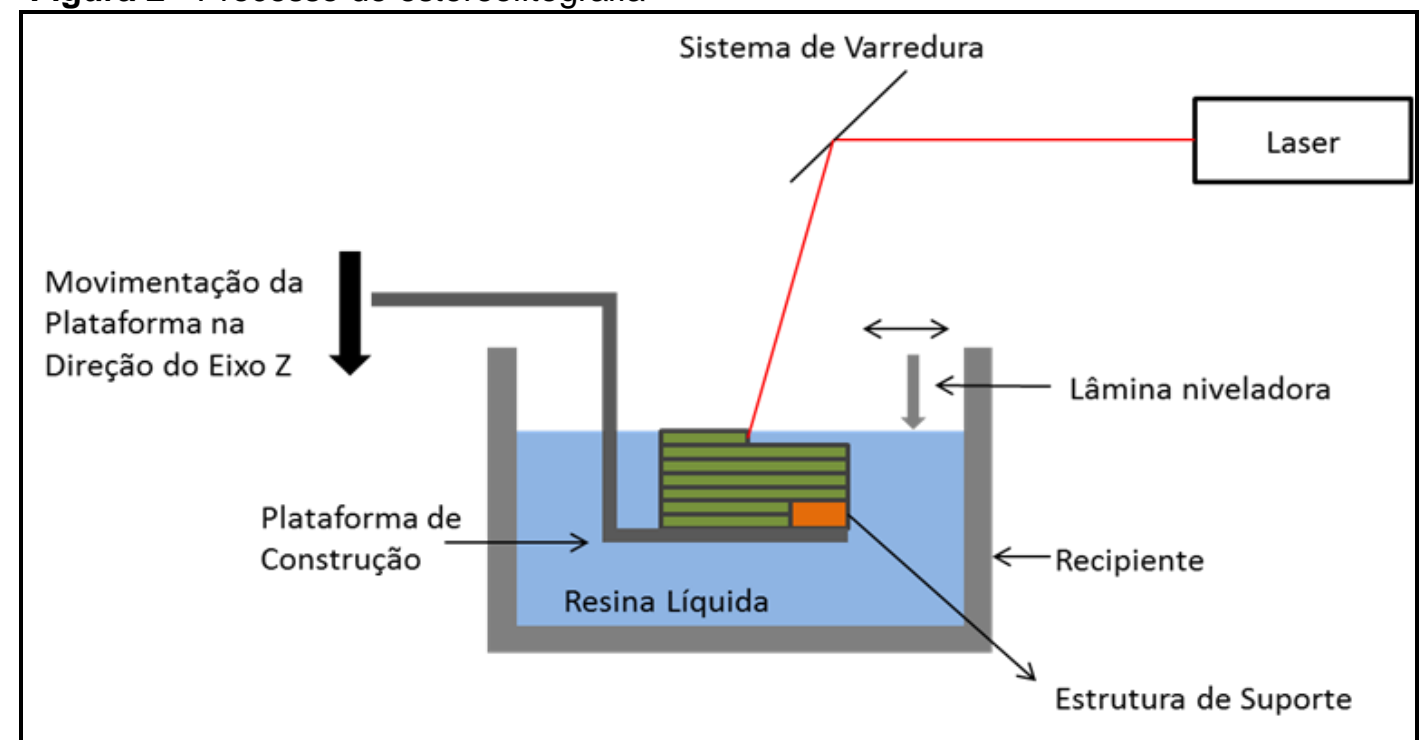

Fonte: Adaptado de Chua, Leong e Lim (2010)

\subsubsection{Sinterização seletiva a laser (SLS)}

A sinterização seletiva a laser foi desenvolvida com o objetivo de permitir a utilização de diferentes materiais como polímeros, cerâmicas e metais na manufatura aditiva e foi primeiramente comercializada em um equipamento na década de 90 pela DTM Corporation, adquirida pela 3D Systems em 2001 (CHUA; LEONG; LIM, 2010).

Na SLS utiliza-se um feixe de laser, direcionado por um sistema de espelhos, para a sinterização seletiva do material em pó sobre uma plataforma, formando as camadas do objeto tridimensional desejado. Após a formação da camada do produto, a plataforma é abaixada, uma nova camada de pó é adicionada e o processo se repete até a formação final do produto. Durante o processo, a plataforma que apoia o produto é aquecida previamente a uma temperatura próxima da temperatura de sinterização do material, facilitando a sinterização pelo feixe de laser e diminuindo o gradiente de temperatura entre o material sinterizado e nãosinterizado (HOPKINSON; HAGUE; DICKENS, 2006; MANÇANARES et al., 2015). Ahrens et al. (2007) ressaltam que a câmara onde estão incluídos a plataforma e o material em pó é mantida em atmosfera inerte e controlada com nitrogênio, evitando a oxidação e reduzindo o risco de explosão das partículas mais finas. A figura 3 ilustra o processo de sinterização seletiva a laser. 
Figura 3 - Processo de Sinterização Seletiva a Laser

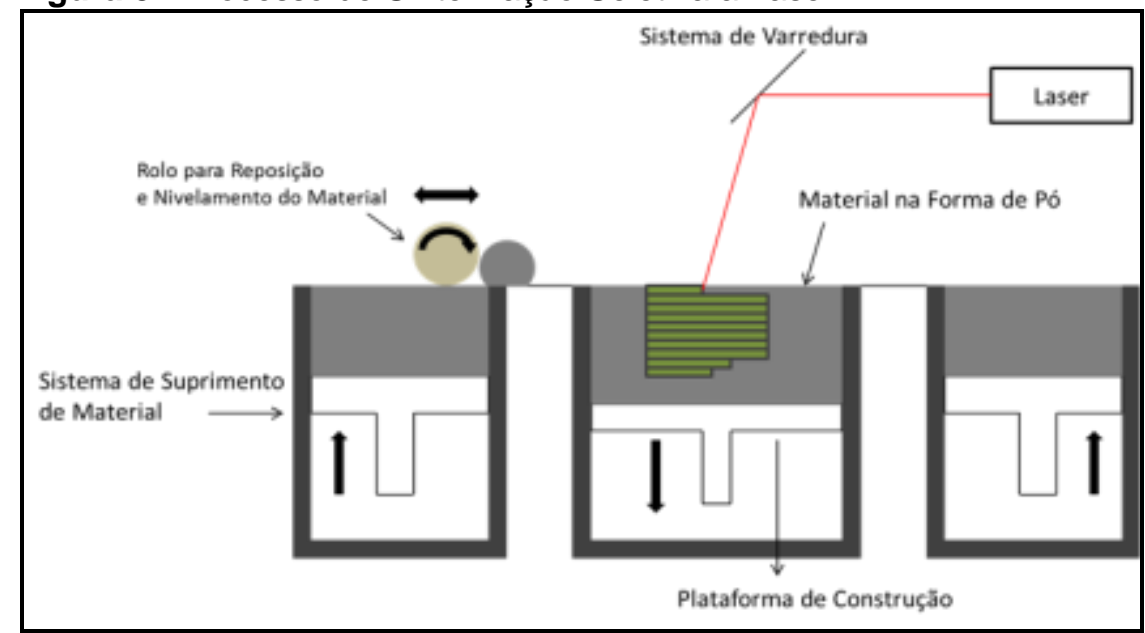

Fonte: Adaptado de Chua, Leong e Lim (2010)

Chua, Leong e Lim (2010) consideram que, em geral, as peças produzidas por esta tecnologia são sólidas o suficiente para não exigirem diversos processos de pós-cura e que a grande vantagem da tecnologia é a alta disponibilidade de materiais, uma vez que diversos materiais tais como plásticos, aços e outros metais, em forma de pó podem ser sinterizados com esta tecnologia.

As tabelas 1 e 2 mostram os materiais compatíveis com duas máquinas de tecnologia SLS de dois fabricantes diferentes, 3D Systems e EOS. Além disso, os autores ponderam ainda que os equipamentos não necessitam da criação de suportes especiais para dar apoio à fabricação das peças, posto que o pó nãosinterizado funciona como suporte estrutural natural para o produto em formação. Ahrens et al. (2007) citam como desvantagens do processo o preço elevado do equipamento e o consumo elevado de energia na sinterização do metal. 
Tabela 1 - Materiais compatíveis com equipamentos de sinterização seletiva a laser (SLS) da 3D Systems

\begin{tabular}{|c|c|}
\hline Material & Aplicação \\
\hline DuraForm ${ }^{\circledR}$ GF plastic & $\begin{array}{l}\text { Poliamida com fibras de vidro resistente para aplicações funcionais. Artigos } \\
\text { esportivos de consumo, protótipos funcionais, pequenos e médios lotes de } \\
\text { produtos, peças que necessitam dureza e resistência térmica. }\end{array}$ \\
\hline DuraForm® PA plastic & $\begin{array}{l}\text { Poliamida durável. Dutos de paredes finas, artigos esportivos de consumo, } \\
\text { painel de veículos, protótipos funcionais, entre outros. }\end{array}$ \\
\hline DuraForm ${ }^{\circledR}$ EX plastic & $\begin{array}{l}\text { Plásticos com alta dureza e resistência a impactos, semelhante à de plásticos } \\
\text { de injeção. Ideal para produção em grandes quantidades de produtos. }\end{array}$ \\
\hline $\begin{array}{l}\text { DuraForm® Flex } \\
\quad \text { plastic }\end{array}$ & Termoplástico elastômero flexível com boa resistência a rasgos. \\
\hline DuraForm $\circledast$ AF plastic & $\begin{array}{l}\text { Poliamida com aparência metálica. Apresenta dureza mecânica e bom } \\
\text { acabamento superficial. }\end{array}$ \\
\hline LaserForm ${ }^{\mathrm{TM}} \mathrm{A} 6$ metal & Ideal para fabricação final de produtos e para ferramental rápido \\
\hline $\begin{array}{l}\text { LaserForm }^{\text {TM }} \text { ST-200 } \\
\text { e LaserForm }{ }^{\text {TM }} \text { ST- } \\
\qquad 100\end{array}$ & $\begin{array}{l}\text { Composto de aço inoxidável para produção de produtos finais ou moldes de } \\
\text { injeção duráveis e resistentes. }\end{array}$ \\
\hline CastForm $^{\mathrm{TM}}$ & aterial a base de poliestireno para produção de $r$ \\
\hline
\end{tabular}

Fonte: Chua, Leong e Lim (2010)

Tabela 2- Materiais compatíveis com equipamentos de sinterização seletiva a laser (SLS) Eosint da EOS

\begin{tabular}{cl} 
Material & \multicolumn{1}{c}{ Aplicação } \\
\hline Aço Inoxidável 15-5 (PH1) & Peças que exijam elevada tenacidade e ductilidade, resistência a \\
Aço inoxidável 17-4 (GP1) & corrosão. Protótipos funcionais, produtos de pequenas séries, \\
& produtos individualizados ou peças sobressalentes. \\
Liga Cobalto Cromo (MP1) & Protótipos, implantes médicos, peças que requerem altas \\
& propriedades mecânicas a temperaturas elevadas e com boa \\
& resistência à corrosão. Peças com paredes finas que necessitam \\
& de resistência e/ou rigidez. Produção em série de peças, \\
& aplicações em turbinas e motores e aplicações médicas. \\
& Peças de turbinas aéreas e terrestres, componentes de aplicação \\
Liga Níquel IN718 & em foguetes e na indústria aeroespacial, poço de petróleo, petróleo \\
& Protótipos funcionais, produtos de pequenas séries, produtos \\
Liga TitaniumTi-64 & individualizados ou peças sobressalentes. Peças que exigem uma \\
& combinação de elevadas propriedades mecânicas e baixo peso \\
& específico. Implantes biomédicos. \\
Liga Alumínio AISi10Mg & Protótipos funcionais, produtos de pequenas séries, produtos \\
& individualizados ou peças sobressalentes. Peças que exigem uma \\
PA 2200 & combinação de boas propriedades térmicas e baixo peso. \\
PA 3200 GF & Poliamida com boa resistência mecânica e térmica \\
\hline
\end{tabular}

Fonte: GPI Prototype \& Manufacturing Services (2014)

Revista Produção Online, Florianópolis, SC, v. 16, n. 2, p. 499-523, abr./jun. 2016. 


\subsubsection{Fabricação da forma final a laser (laser engineered net shape - LENS)}

A empresa Optomec, Inc. comercializa desde 1997 um processo denominado fabricação da forma final a laser (laser engineered net shaping - LENS), que utiliza um laser de alta potência sobre uma superfície da peça sendo fabricada, para fundir o material e formar a camada do produto (AHRENS et al., 2007). O cabeçote de deposição possui um feixe de laser no seu centro com dois a quatro bicos de deposição localizados ao redor do laser (KARUNAKARAN et al., 2012). As diferenças para o processo de sinterização seletiva a laser estão na maneira pela qual o material é adicionado, aqui sendo depositado por um instrumento próximo ao laser, e no fato de o processo resultar na completa fusão do material e produzir peças maciças e resistentes de metal (AHRENS et al., 2007). A figura 4 apresenta uma representação do processo LENS.

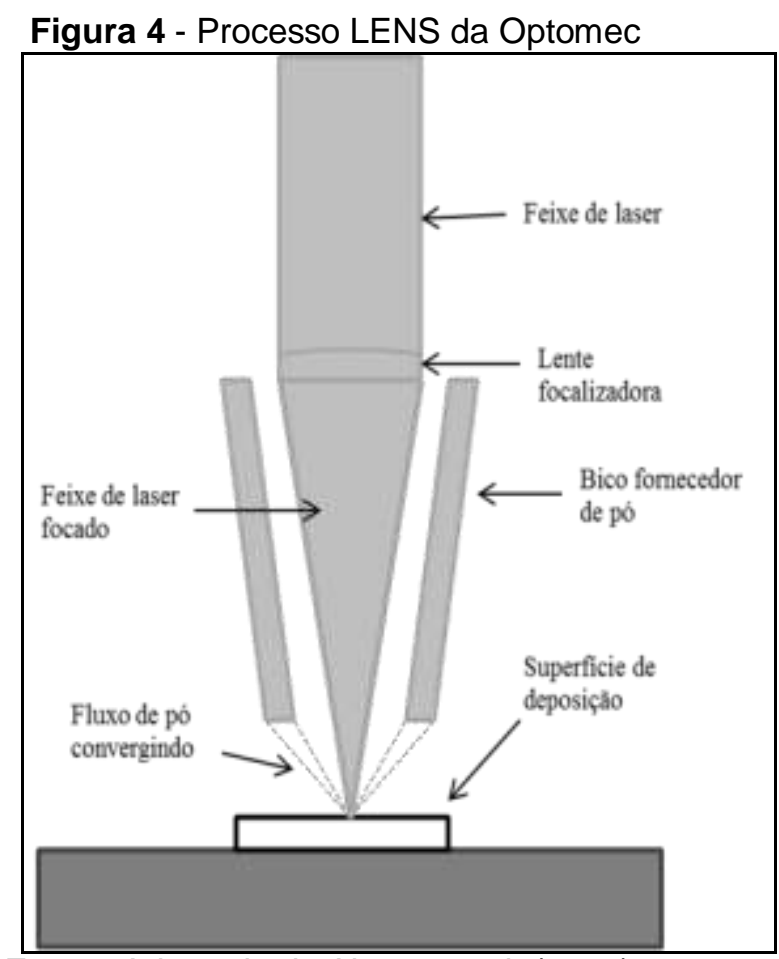

Fonte: Adaptado de Ahrens et al. (2007)

\subsubsection{Fusão por feixe de elétrons (EBM)}

A empresa Arcam possui um processo denominado electron beam melting (EBM), ou fusão por feixe de elétrons, comercializado pela primeira vez em 2001. 
Esta técnica é utilizada para produção de peças metálicas maciças e resistentes, e utiliza o princípio da total fusão do material em pó em uma câmara a vácuo por um feixe de elétrons para formação da camada. Após a formação da camada, uma nova camada de pó é adicionada e repete-se o processo. Dentre os materiais disponíveis estão ligas de titânio como Ti6A14V (ASTM 136), Ti6A14V ELI (ASTM F136), Titanium Grade 2 (ASTM F67) e liga de cobalto e cromo (ASTM F75). É importante destacar que o titânio e suas ligas são materiais especiais, de alta dureza e alto custo, usado em atividades com alta exigência mecânica, como estruturas aeronáuticas, próteses e outros. O processo resulta em peças com bom acabamento superficial mas possui um elevado consumo de energia. Ressalta-se também a necessidade de se manter a câmara de produção em vácuo a fim de garantir a qualidade da peça e a segurança do operador do equipamento (CHUA; LEONG; LIM, 2010).

\subsubsection{Modelagem por deposição de material fundido (FDM)}

$\mathrm{Na}$ modelagem por deposição de material fundido (FDM), filamentos de uma resina termoplástica são extrudados, a altas temperaturas, sendo depositados sobre uma plataforma de construção. O bico extrusor está ligado a um cabeçote que se movimenta no plano X-Y, paralelo ao plano da plataforma, distribuindo o material de acordo com a geometria da camada em construção. Ao entrar em contato com a plataforma, que se encontra em temperatura inferior ao material extrudado, 0 filamento depositado é rapidamente endurecido, formando uma camada da peça a ser produzida. Ao término da deposição da camada, a plataforma é abaixada na direção do eixo $Z$, reiniciando-se o processo de deposição e formando uma nova camada sobre a anterior. Este processo se repete sucessivamente até a formação final do objeto (UPCRAFT; FLETCHER, 2003; MANÇANARES et al., 2015).

Segundo Ahrens et al. (2007), de acordo da geometria da peça a ser produzida, torna-se frequentemente necessária a produção de um suporte para apoiá-la estruturalmente, assim como ocorre na estereolitografia. Este suporte é produzindo por um bico extrusor extra e com um material diferente do material utilizado para construir a peça e sua principal função é permitir a construção de 
regiões não conectadas à peça durante sua fabricação; o suporte deve ser removido após a produção na máquina.

Para Hopkinson, Hague e Dickens (2006), o processo que foi inicialmente comercializado pela Stratasys em 1991 possui sua velocidade limitada pelo fato de a cabeça extrusora precisar percorrer toda a área de cada camada a ser construída. Entretanto, ressaltam que os equipamentos de FDM são fáceis de serem instalados, podendo ser utilizados tanto em ambientes de escritórios quanto em fábricas. Para Kai et al. (2003) apud AHRENS et al., 2007, é possível criar com FDM peças funcionais que apresentam $85 \%$ da resistência de peças produzidas a partir do processo de injeção com o mesmo material.

Segundo a Stratasys, empresa pioneira na tecnologia FDM e que hoje faz parte da 3D Systems, a lista de materiais disponíveis para esta tecnologia inclui ceras, poliésteres, ABS (Acrilonitrila Butadieno Estireno), policarbonatos (PC) e polifenilsulfona (PPSF) (STRATASYS, 2014). A figura 5 ilustra o processo de deposição de material fundido.

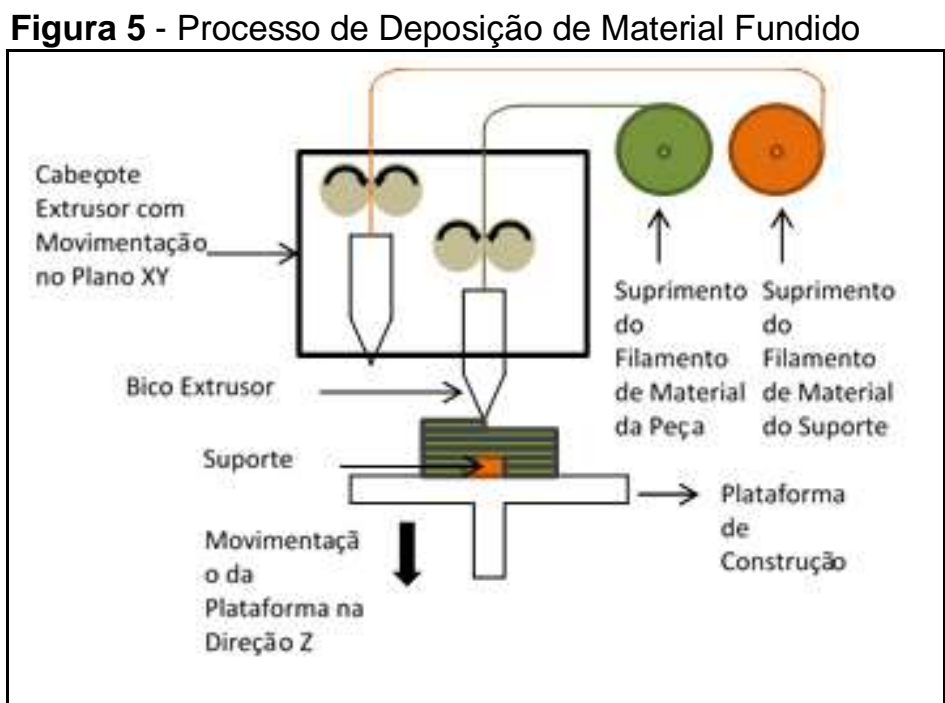

Fonte: Adaptado de Ahrens et al. (2007)

\subsubsection{Impressão por Jato de Tinta (IJP)}

No processo de modelagem por jato de tinta, um material foto curável é depositado sobre uma plataforma, na forma de pequenas gotas, por um cabeçote com movimentação no plano X-Y. Logo após sua deposição, o material é curado 
por luz ultravioleta emitida, também, pelo cabeçote, formando a camada da peça. Em seguida, repete-se o processo para formação das demais camadas da peça. $O$ material para formação de estruturas de suporte, que deverão ser removidas após o processo de modelagem, é depositado simultaneamente por outro jato de impressão (AHRENS et al., 2007; MANÇANARES et al., 2015).

Para os autores, este método apresenta alta precisão e boa qualidade superficial, permitindo sua utilização em diversas aplicações. Entretanto, a quantidade de materiais disponíveis para o processo é limitada, restringindo-se às resinas poliméricas e termoplásticos. A figura 6 ilustra o princípio do processo IJP.

Figura 6 - Princípio de funcionamento do processo de impressão por jato de tinta (IJP)

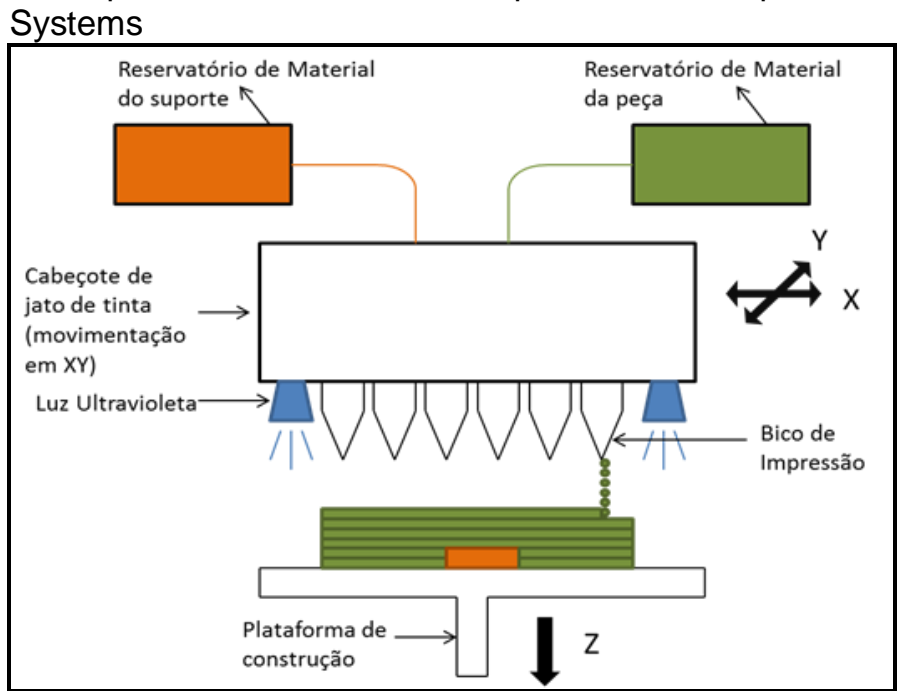

Fonte: Adaptado de Ahrens et al. (2007)

\subsubsection{Impressão Tridimensional (3DP)}

A técnica de impressão tridimensional baseia-se nas impressoras convencionais de tinta presentes em casas e escritórios de hoje em dia. Foi desenvolvida no Massachusetts Institute of Technology (MIT) e licenciada para diversas empresas. As peças são construídas em um recipiente de material em pó, semelhante ao processo de sinterização seletiva a laser (SLS), sobre uma plataforma que se locomove perpendicularmente ao plano de formação das camadas do objeto. Um cabeçote que se locomove no plano XY deposita um agente aglutinante por impressão do tipo jato de tinta sobre o a plataforma, de acordo com a geometria da camada do objeto a ser construído. Após a formação da camada, a

Revista Produção Online, Florianópolis, SC, v. 16, n. 2, p. 499-523, abr./jun. 2016. 
plataforma é abaixada e um rolo é acionado, adicionando mais material e garantindo o nivelamento do pó no reservatório. Assim como na SLS, não é necessário suporte no processo, uma vez que o material não aglutinado, na forma de pó, funciona como apoio estrutural à peça em construção (UPCRAFT; FLETCHER, 2003).

Segundo Ahrens et al. (2007), poder-se-ia, teoricamente, utilizar na impressão tridimensional qualquer material que possa ser transformado em pó, sendo necessário um agente aglutinante específico para cada material. Os materiais mais utilizados são metais, polímeros, cerâmica, gesso e um composto à base de amido e celulose. Os autores mencionam, também, que a peça produzida com esta tecnologia é frágil, necessitando de pós-processamento para apresentar maior resistência. Para metais, deve-se realizar dois ciclos de aquecimento da peça em forno a alta temperatura como pós-processamento, enquanto que para os demais materiais deve-se realizar infiltração com ceras ou resinas para garantir maior resistência à peça, ou com compostos à base de uretano, garantindo flexibilidade à peça.

Figura 7 - Processo de Impressão Tridimensional

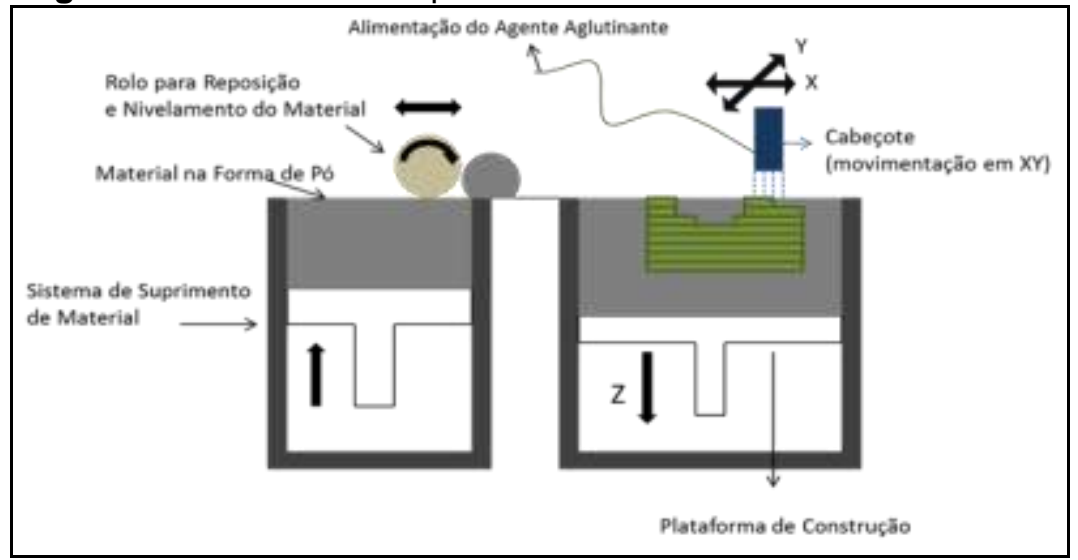

Fonte: adaptado de Upcraft e Fletcher (2003)

\section{METODOLOGIA}

Visando ao estabelecimento de um padrão para o acompanhamento do custo de produção por manufatura aditiva, definiu-se uma peça cuja produção seria cotada em diferentes quantidades tanto em produção por manufatura aditiva quanto por meios convencionais. Para a determinação da peça padrão, foi definida uma série de requisitos que a peça deveria apresentar a fim de satisfazer restrições do estudo e de sua produção em escala nacional e internacional, entre os quais estão:

Revista Produção Online, Florianópolis, SC, v. 16, n. 2, p. 499-523, abr./jun. 2016. 
1. Peça única que não requer montagem: o produto final deverá conter uma única peça, isto é, não poderá conter em seu processo produtivo montagem ou junção de diversas partes. Desta forma, procura-se simplificar o processo de produção e de comparação entre os meios produtivos além de reduzir eventuais erros associados ao processo de montagem.

2. Tamanho máximo nas dimensões $X, Y$ e $Z$ : os equipamentos de manufatura aditiva possuem como uma de suas restrições de operação o tamanho máximo de uma peça a ser produzida, dado por dimensões máximas nos eixos $\mathrm{X}, \mathrm{Y}$ e Z $\mathrm{Z}$. Isto ocorre porque a área da plataforma de construção é finita e diferente para cada modelo de equipamento. Assim, existe um volume máximo que uma peça pode ter, com tamanho limitado em todas as dimensões.

3. Possibilidade de produção em alta escala: Uma vez que o estudo procura comparar os custos de produção de uma peça única e de um grande lote, representando a produção em massa, é imprescindível que a peça padrão escolhida seja fabricada em ambas as escalas.

4. Viabilidade de produção por manufatura aditiva: a peça padrão escolhida deve ter sua produção viável por manufatura aditiva. Ou seja, os equipamentos de manufatura aditiva presentes no mercado deverão ser capazes de produzir a peça, de acordo com sua geometria e dimensão.

5. Geometria complexa: a peça escolhida deverá apresentar uma geometria relativamente complexa a fim de ressaltar vantagens produtivas da manufatura aditiva. Parte-se da premissa de que uma geometria complexa pode implicar em processos de fabricação diferenciados e complexos como, por exemplo, uma usinagem específica mais demorada e complexa, que pode levar ao aumento do custo do produto.

Partindo deste conjunto de hipóteses para as peças, foi possível restringir e comparar as opções disponíveis, com o objetivo de escolher a peça a ser utilizada no estudo. Optou-se pela escolha de uma engrenagem cilíndrica reta de módulo 3 , diâmetro externo de $78 \mathrm{~mm}$, comprimento de face de $20 \mathrm{~mm}$ e furo no centro de 20 mm de diâmetro. A peça padrão é ilustrada na figura 8. 
Figura 8 - Ilustração da peça padrão escolhida
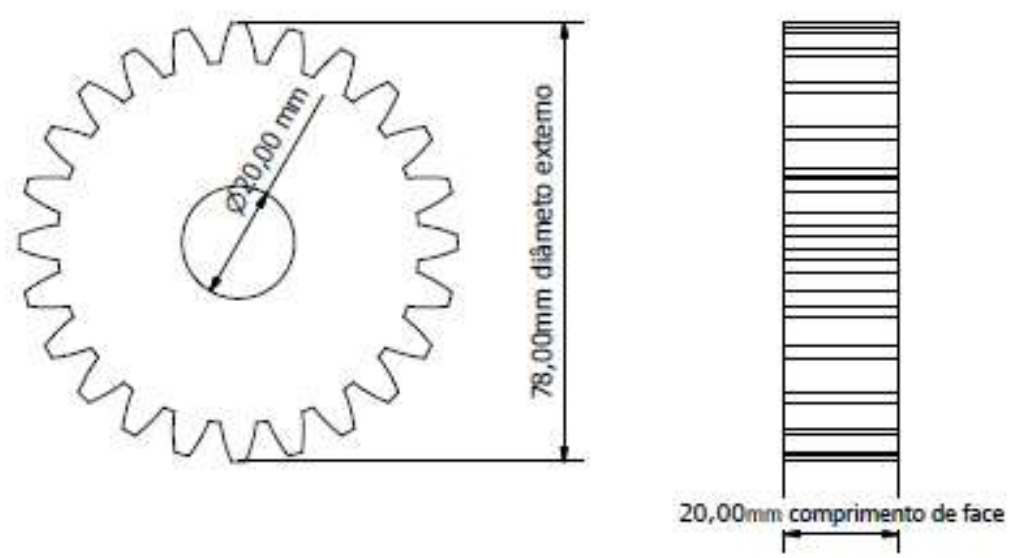

A cotação orçamentária para produção da peça padrão, tanto por manufatura aditiva quanto por métodos convencionais, foi realizada por solicitação direta às empresas nacionais e internacionais, com base no modelo 3D e nas características da peça.

\section{RESULTADOS}

Optou-se por realizar a cotação de peça única por manufatura aditiva e em pequena, média e grande escala de produção, por meios convencionais. Assim, foi realizada a cotação em empresas fornecedoras de serviços de manufatura aditiva bem como ferramentarias capazes de produzir a peça por meios convencionais.

Foi definido aço 1020 como material a ser cotado em ferramentarias. Para este material, a técnica de produção por manufatura aditiva indicada seria Direct Metal Laser Sintering (DMSL), que representa uma variação do SLS (subseção 2.2.2), de alto custo e pouco disponível. O material utilizado na produção por manufatura aditiva foi o GP1. Trata-se de aço em pó produzido pela Electro Optical Systems, otimizado para os seus equipamentos de manufatura aditiva.

Como no Brasil não foi encontrada nenhuma empresa que forneça serviços com esta tecnologia, tornou-se necessária a cotação em empresas no exterior. Foram realizadas cotações em três empresas de manufatura aditiva (representadas como Manufatura Aditiva A, B e C) e em cinco empresas para processos convencionais (representadas como Ferramentaria D, E, F, G e H). Os resultados das cotações realizadas são apresentados na Tabela 3. 
Tabela 3 - Cotação da produção por manufatura aditiva e por métodos convencionais

\begin{tabular}{|c|c|c|c|}
\hline Empresa & Método & $\begin{array}{c}\text { Quantidade } \\
\text { encomendada }\end{array}$ & Preço unitário ${ }^{1}$ \\
\hline & & 1 & USD $\$ 1.529,60$ \\
\hline Manufatura Aditiva A & & 3 & USD $\$ 1.164,61$ \\
\hline & Manufatura Aditiva & 5 & USD $\$ 988,99$ \\
\hline Manufatura Aditiva B & & 1 & USD $\$ 1.543,00$ \\
\hline Manufatura Aditiva C & & 1 & USD $\$ 856,93$ \\
\hline Ferramentaria D & & 1 & USD $\$ 128,99$ \\
\hline Ferramentaria $\mathrm{E}$ & & 1 & USD $\$ 127,65$ \\
\hline Ferramentaria $\mathrm{F}$ & & 1 & USD $\$ 67,18$ \\
\hline Ferramentaria G & & 1 & USD $\$ 116,45$ \\
\hline & Convencional & 1 & USD $\$ 67,18$ \\
\hline Ferramentaria $\mathrm{H}$ & & 100 & USD $\$ 11,19$ \\
\hline (Alta Escala) & & 1000 & USD $\$ 8,95$ \\
\hline
\end{tabular}

Ressalta-se que as empresas consultadas para cotação por manufatura aditiva estão localizadas no exterior e os valores não incluem fretes e impostos de importação.

A análise das cotações indica que o custo de obtenção de uma peça por manufatura aditiva ainda é superior à produção de uma peça única por método convencional. Entretanto, na encomenda de cinco peças por manufatura aditiva, por exemplo, observa-se um custo por peça ligeiramente menor. Em teoria, conforme discutido no item 2, não deveria haver economia de escalas significantes na produção por manufatura aditiva, uma vez que se paga apenas pelo material a mais consumido e o tempo de produção que inclui a energia necessária para produção, configurando-se como custos variáveis. A diferença do valor unitário ao encomendar-se uma peça (USD $\$ 1.529,60$ por peça) e cinco peças (USD $\$ 988,99$ por peça) ocorre neste caso devido à possibilidade de otimização de ocupação de máquina em uma rodada de produção com ganhos de setup da máquina, adaptação do modelo digital à máquina específica e, principalmente, devido ao tempo de utilização da máquina. Segundo as fornecedoras do serviço de manufatura aditiva cotadas, na tecnologia selecionada (DMLS), o tempo de utilização da máquina é o principal fator de custo e o tempo para o laser percorrer toda a superfície é mínimo

\footnotetext{
${ }^{1}$ Para conversão das cotações realizadas em Real (BRL) para Dólares Americanos (USD) utilizou-se o fator de USD $\$ 0,4479$ do dia 15/04/2014, época da tomada de preços com os fornecedores.

Fonte: Bloomberg (2014).
}

Revista Produção Online, Florianópolis, SC, v. 16, n. 2, p. 499-523, abr./jun. 2016. 
comparado com o tempo de recobrimento da camada de pó. Assim, quanto mais peças couberem em uma plataforma, menor o custo final unitário.

Quanto à produção por métodos convencionais, notou-se um preço médio (média de todas as cotações obtidas no período) de USD $\$ 101,49$ para produção de uma peça única. Este valor está muito abaixo daquele praticado para obtenção de uma peça única por manufatura aditiva. Considerando o cenário onde há máxima utilização do equipamento de produção por manufatura aditiva, com a produção de cinco peças em uma única plataforma, o custo unitário, USD $\$ 988,99$, mostra-se ainda bastante superior frente à produção unitária por métodos convencionais. Este valor é ainda distante também do valor unitário obtido quando há produção em alta escala, como mostrado no gráfico da figura 9, em que a encomenda de 1.000 unidades resulta em um valor unitário de USD \$8,95.

Para comparação com produção de grandes lotes por métodos convencionais, a manufatura aditiva é ainda menos competitiva, dado que existem grandes economias de escala na produção destas quantidades por métodos convencionais e a produção de engrenagens é um processo já dominado e conhecido pela indústria.

Figura 9 - Comparação entre os custos unitários dos métodos convencionais de 1 unidade e alta escala com os métodos de manufatura aditiva de 1 unidade e lote de 5 peças

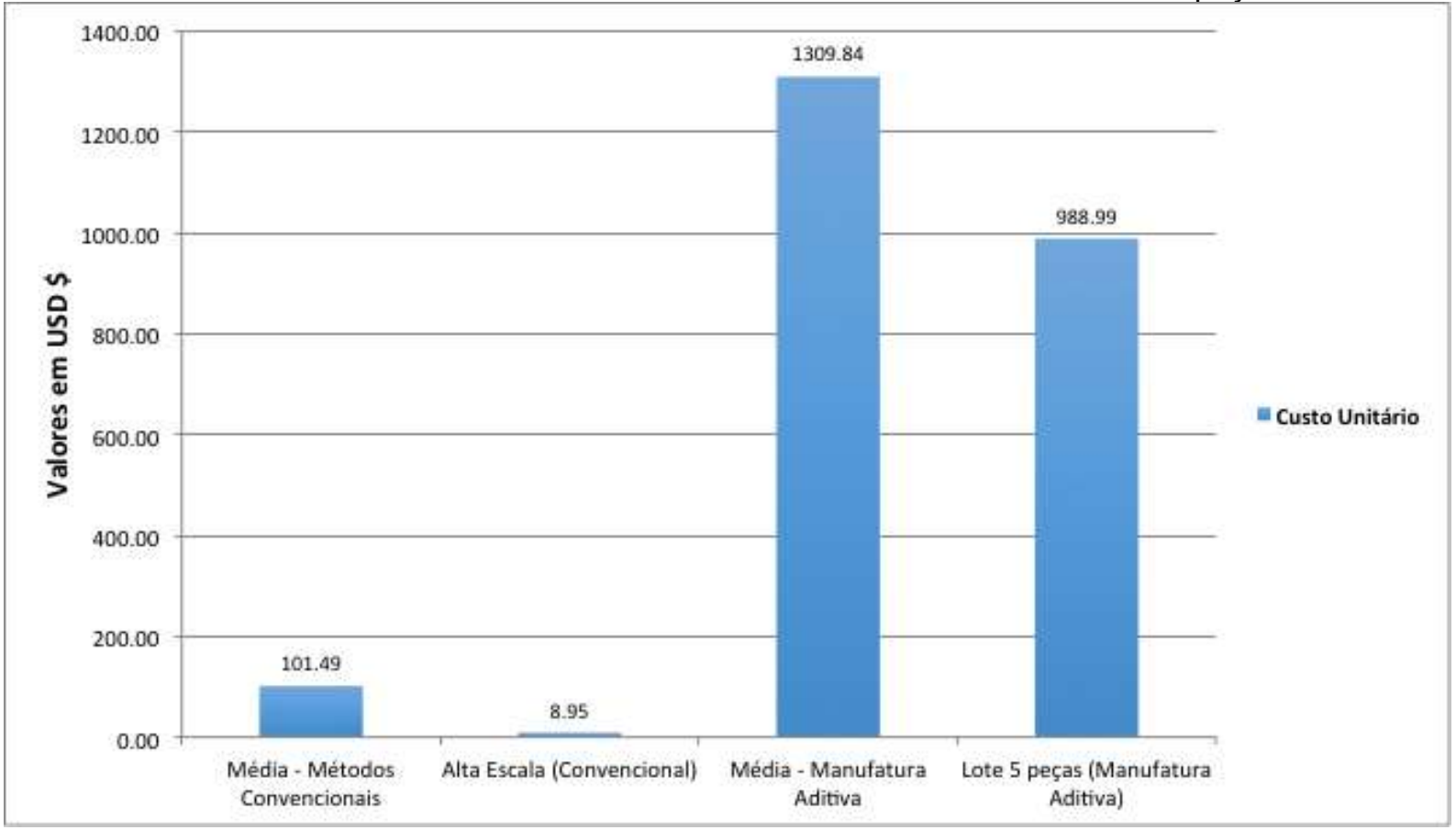

Revista Produção Online, Florianópolis, SC, v. 16, n. 2, p. 499-523, abr./jun. 2016. 
Espera-se que esta diferença de custo entre a produção por manufatura aditiva e por métodos convencionais diminua de acordo com o aumento da complexidade da geometria e, consequentemente, a dificuldade de produção da peça por métodos convencionais. Além disso, espera-se também que a diferença de custo diminua com o amadurecimento da tecnologia de manufatura aditiva. $O$ método de acompanhamento da evolução de custos proposto por este artigo deve possibilitar o monitoramento dessa tendência ao longo do tempo.

Em comparação com resultados obtidos por outros pesquisadores, destacase o trabalho de Atzeni e Salmi (2012), que reconhecem que a maior parte dos estudos de custos de manufatura aditiva disponíveis atualmente focam na análise da produção de ferramentais e moldes metálicos em detrimento da fabricação direta e final de peças metálicas. Segundo os autores, isso se deve em grande parte ao fato de a produção de peças metálicas por meio da manufatura aditiva ser um fato recente. Entretanto ressaltam que pesquisas e desenvolvimento de novos materiais e equipamentos já permitem hoje a produção de peças metálicas finais por manufatura aditiva para os setores aeroespacial e médico. Em seu estudo, os autores comparam os custos de fabricação de um trem de pouso do avião italiano P180 Avant II na escala de 1:5, redesenhando a peça para aproveitar as vantagens de design proporcionadas pela manufatura aditiva. No caso estudado, a peça produzida por manufatura aditiva teve custo de 526,31 euros por peça. Já na produção por métodos convencionais utilizando moldes, o custo do molde (21.000 euros) é repartido pelo número de peças produzida além de existir também um custo variável de 21,29 euros por peça (incluindo montagem). Os autores identificaram em 42 o número de peças a partir do qual a produção por métodos convencionais tornase economicamente vantajosa para o caso estudado.

Adicionalmente, Hopkinson e Dickens (2003) analisaram os custos de produção de peças plásticas por diferentes processos de manufatura aditiva, comparando-os com o método convencional de injeção em moldes. Desconsiderando eventuais diferenças nas propriedades dos materiais utilizados, de acabamento e precisão dimensional dos processos produtivos empregados, realizase uma comparação de custos em função da quantidade a ser produzida. Para uma alavanca plástica de $35 \mathrm{~mm}$ de comprimento, os autores calcularam um custo por peça de 5,25 euros para a SLA (subseção 2.2.1), 2,20 euros para a SLS (subseção 
2.2.2) e 4,47 euros para FDM (subseção 2.2.5). Para o processo tradicional de injeção em moldes calculou-se um custo variável de 0,23 euros por peça e o investimento em ferramental (molde) de 27.360 euros.

Em um contraponto, Ruffo et al. (2006) mostraram que, no estudo de Hopkinson e Dickens (2003), era possível obter pequenas variações no custo identificado para as peças de manufatura aditiva, dependendo do método de rateio utilizado e que no processo SLS existem certas economias de escala na medida em que a partir de certas quantidades produzidas, pode-se obter ganhos com a mudança da orientação das peças (vertical ou horizontal) otimizando o volume útil de produção do equipamento utilizado.

Outros autores como Piili et al. (2015), concentram-se na identificação e análise do rateio da aquisição de um equipamento de manufatura aditiva e produção de peças, não realizando comparações com métodos convencionais. Nestes casos, o interesse da análise é compreender os fatores que compõe o custo de produção de peças com manufatura aditiva, identificando potenciais áreas e estratégias para otimizar o processo.

Importante ressaltar que esses estudos consideram o custo de produção a partir da identificação e rateio dos custos do processo produtivo, como aquisição de um equipamento de manufatura aditiva, custo de material, mão de obra entre outros. Trata-se, portanto, de método diferente da abordagem empregada neste estudo, que se concentrou em analisar pequenas séries de produção a serem produzidas por fabricantes externos como indicadores da evolução de custos na indústria da manufatura aditiva.

\section{CONCLUSÕES E TRABALHOS FUTUROS}

Esta pesquisa estabelece um modelo padrão para realizar 0 acompanhamento da evolução dos custos de processos de manufatura aditiva ao longo do tempo, com base na coleta de dados empíricos para uma peça padrão (peça, suas características de projeto e tamanho de lote).

Apesar de ainda existir uma grande diferença de custos entre os métodos de manufatura aditiva e os convencionais, existe expectativa de redução de custos, impulsionada pelo amadurecimento da tecnologia e aumento da velocidade de

Revista Produção Online, Florianópolis, SC, v. 16, n. 2, p. 499-523, abr./jun. 2016. 
produção. Os próximos anos serão determinantes na medida em que se perceberá quão forte é esta tendência de redução de custos e até que ponto esta tendência se manterá.

É importante salientar que, do mesmo modo que há uma tendência para redução de custos da manufatura aditiva, há também uma tendência de aprimoramento técnico para as peças produzidas. Com o desenvolvimento das tecnologias, peças mais resistentes e mais similares às peças obtidas por meios convencionais serão produzidas. Essa evolução em qualidade das peças é importante uma vez que em inúmeras aplicações, a resistência à tração e à fadiga são características determinantes das peças, como por exemplo em peças fornecidas para a indústria automobilística e aeronáutica.

Futuras cotações utilizando o padrão definido neste artigo permitirão identificar melhor as tendências de evolução do custo da manufatura aditiva nos próximos anos, definindo se este método será competitivo na produção de itens únicos, em lotes médios ou na produção em massa de produtos. É possível também utilizar o padrão estabelecido para analisar a tendência hipotética de redução e estabilização de custos da manufatura aditiva, baseada nos conceitos de economias de escala, curvas de aprendizado e aprimoramento da tecnologia. Em conjunto com análises do custo de fabricação por manufatura aditiva, deve-se manter o constante monitoramento das aplicações e da adoção da tecnologia na indústria bem como a evolução das qualidades das peças produzidas a fim de confirmar, ou não, o caráter disruptivo desta tecnologia.

\section{AGRADECIMENTOS}

Os autores agradecem o apoio financeiro fornecido pela Fundação de Amparo à Pesquisa do Estado de São Paulo (FAPESP) para a execução deste trabalho.

\section{REFERÊNCIAS}

ACHILLAS,C.; AIDONIS, D.; IAKOVOU, E.; THYMIANIDIS, M.; TZETZIS, D. A methodological framework for the inclusion of modern additive manufacturing into the production portfolio of a focused factory. Journal of Manufacturing Systems, v. 37, p. 328339, 2015. http://dx.doi.org/10.1016/j.jmsy.2014.07.014 
AHRENS, C. H.; FERREIRA, C. B.; PETRUSH, G.; CARVALHO, J. D.; SANTOS, J. R. L. D.; SILVA, J. V. L. D.; VOLPATO, N. Prototipagem Rápida - Tecnologias e Aplicações. 1. ed. São Paulo: Edgar Blücher, 2007.

ATZENI E., SALMI, A. Economics of Additive Manufacturing for End-usable Metal parts. International Journal of Advanced Manufacturing Technology, v. 62, p. 1147-1155, 2012. http://dx.doi.org/10.1007/s00170-011-3878-1

BERMAN, Barry. 3-D printing: The new industrial revolution. Business Horizons, v. 55, n. 2, p. 155-162, 2012. http://dx.doi.org/10.1016/j.bushor.2011.11.003

BLOOMBERG. Currencies: MAJOR WORLD CURRENCIES. 2014. Disponível em: < http://www.bloomberg.com/quote/BRLUSD:CUR/>. Acesso em: 14 dez. 2014.

CAMPBELL, I.; BOURELL, D.; GIBSON, I. Additive manufacturing: rapid prototyping comes of age. Rapid Prototyping Journal, v. 18, n.4, p. 255 - 258, 2012.

http://dx.doi.org/10.1108/13552541211231563

CARTER, W. Additive manufacturing at GE: opportunities and challenges. In: ABIMAQ INOVA - INDÚSTRIA DO FUTURO, 2014, São Paulo. Disponível em: < http://www.ipdmaq.org.br/site.aspx/Abimaq_Inova>. Acesso em: 29 dez. 2014.

CHUA, C.K.; LEONG, K.F.; LIM, C.S. Rapid Prototyping: Principles and Applications in Manufacturing. Singapura: World Scientific, 2010. http://dx.doi.org/10.1142/6665

GARTNER, J.; MARESCH, D.; FINK, M. The Potential of Additive Manufacturing for Technology Entrepreneurship: An Integrative Technology Assessment. Creativity and Innovation Management, v. 24, n. 4, p. 585-600, 2015.

http://dx.doi.org/10.1111/caim.12132

GIBSON, I.; ROSEN, D. W.; STUCKER, B. Additive manufacturing technologies: rapid prototyping to direct Digital manufacturing. 1. ed. Nova York: Springer, 2009.

GPI PROTOTYPE \& MANUFACTURIG SERVICES. DMLS Materials \& Specifications.

Disponível em: <http://www.gpiprototype.com/dmls-materials.html>. Acesso em: 11 fev. 2014

HÖLMSTROM, J.; PARTANEN, J.; TUOMI, J.; WALTER, M. Rapid manufacturing in the spare parts supply chain: alternative approaches to capacity deployment. Journal of Manufacturing Technology Management. v. 21, n. 6, p. 687-697. 2010.

http://dx.doi.org/10.1108/17410381011063996

HOPKINSON, N.; DICKENS, P.M. Analysis of rapid manufacturing-using layer manufacturing processes for production. Proceedings of the Institute of Mechanical Engineers, Part C: Journal of Mechanical Engineering Science, London, p.31-39, 2003. http://dx.doi.org/10.1243/095440603762554596

HOPKINSON, N,; HAGUE, R.J.M.; DICKENS, P.M. Rapid manufacturing: an industrial revolution for the digital age. Chichester: John Wiley \& Sons, 2006.

http://dx.doi.org/10.1002/0470033991

KARUNAKARAN, K.P.; BERNARD, A.; SURYAKUMAR, S.; DEMBINSKI, L.; TAILLANDIER, G. Rapid manufacturing of metallic objects. Rapid Prototyping Journal, v. 18, n. 4, p.264 280. 2012. http://dx.doi.org/10.1108/13552541211231644

Revista Produção Online, Florianópolis, SC, v. 16, n. 2, p. 499-523, abr./jun. 2016. 
KIM, D.; DENNO, P.; JONES, A. A model-based approach to refine process parameters in smart manufacturing. Concurrent Engineering, v. 23, n. 4, p. 365-376, 2015.

http://dx.doi.org/10.1177/1063293x15591038

LAN, Po-Ting; CHOU, Shuo-Yan; CHENT, Lin-Lin; GEMMILL, Douglas. Determining fabrication orientations for rapid prototyping with stereolithography apparatus. ComputerAided Design, v. 2, n. 1, p. 53-62, 1997. http://dx.doi.org/10.1016/s0010-4485(96)00049-8

MANÇANARES, C.; ZANCUL, E.S. CAVALCANTE, J.; CAUCHICK MIGUEL, P. Additive manufacturing process selection based on parts' selection criteria. The International Journal of Advanced Manufacturing Technology, v. 80, n. 5-8, p. 1007-1014, 2015. http://dx.doi.org/10.1016/s0010-4485(96)00049-8

McKinsey Global Institute. Disruptive technologies: advances that will transform life, business, and the global economy. Maio, 2013.

PIILI, H., HAPPONEN, A., VÄISTÖ, T., VENKATARAMANAN, V., PARTANEN, J. SALMINEN, A. Cost Estimation of Laser Additive Manufacturing of Stainless Steel. [ed.] Elsevier. Physics Procedia. v. 78, pp. 388-396, 2015.

http://dx.doi.org/10.1016/j.phpro.2015.11.053

RUFFO, M., TUCK, C. E HAGUE, R. J. M. Cost estimation for rapid manufacturing - laser sintering production for low to medium volumes. Proceedings of the Institution of Mechanical Engineers, Part B: Journal of Engineering Manufacture, v. 220, n. 9, p. 1417-1427, 2006. http://dx.doi.org/10.1243/09544054jem517

SEALEY, W. Additive manufacturing as a disruptive technology: how to avoid the pitfall. American Journal of Engineering and Technology Research, v. 12, n. 1, p. 86-93, 2012. http://dx.doi.org/10.1109/emr.2013.6693939

STRATASYS. FDM Thermoplastics. Disponível em <http://www.stratasys.com/materials/fdm>. Acesso em: 11 fev. 2014.

THE ECONOMIST. The Third industrial Revolution. Disponível em: http://www.economist.com/node/21552901 acesso em: 06 fev. 2012.

UPCRAFT, S.; FLETCHER, R. The rapid prototyping technologies. Assembly Automation, v. 23, n, 4, p. 318-330, 2003. http://dx.doi.org/10.1108/01445150310698634

WIRED, The New MakerBot Replicator Might Just Change Your World. Disponível em: <http://www.wired.com/design/2012/09/how-makerbots-replicator2-will-launch-era-ofdesktop-manufacturing/all/>. Acesso em: 06 fev. 2012.

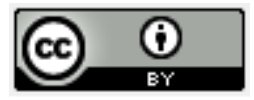

Artigo recebido em 29/12/2014 e aceito para publicação em 06/04/2016

DOI: http://dx.doi.org/ 10.14488/1676-1901.v16i2.1963 